\title{
Summary Abstract: Carbon monoxide oxidation catalysis over $\operatorname{Ir}(110)^{a)}$
}

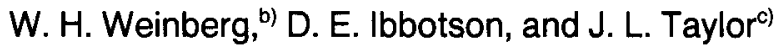 \\ Division of Chemistry and Chemical Engineering, California Institute of Technology, Pasadena, California 91125 \\ (Received 11 August 1980; accepted 29 October 1980)
}

PACS numbers: $82.65 . \mathrm{Jv}, 82.80 . \mathrm{Ms}$

The heterogeneously catalyzed reaction of $\mathrm{CO}$ and $\mathrm{O}_{2}$ to form $\mathrm{CO}_{2}$ over $\operatorname{Ir}(110)$ has been studied through measurements of both the transient kinetics of the various elementary reactions that might limit the steady state rate ${ }^{1}$ as well as the steady state rates under various conditions. ${ }^{2}$ The elementary reactions that are relevant include the adsorption of $\mathrm{CO}$, the adsorption of oxygen, the desorption of $\mathrm{CO}$, and the oxidation of $\mathrm{CO}$ via the Langmuir-Hinshelwood mechanism. Mass spectrometry was used to develop rate expressions for these elementary reactions under transient conditions and to measure the steady state rates of $\mathrm{CO}_{2}$ production.

Transient Experiments ${ }^{1}$ : The nonreactive coadsorption and subsequent reaction of $\mathrm{CO}$ and oxygen on $\operatorname{Ir}(110)$ under transient conditions focus on the following: (1) The dependence of the rate expressions for CO desorption and CO oxidation upon the composition of the adlayer, and (2) the competitive adsorption of $\mathrm{CO}$ and oxygen. Several thermal desorption spectra of $\mathrm{CO}, \mathrm{O}_{2}$, and $\mathrm{CO}_{2}$ were obtained by flashing coadsorbed layers of $\mathrm{CO}$ and oxygen from clean and oxidized $\operatorname{Ir}(110)$ at a constant heating rate. Activation energies and pre-exponential factors for $\mathrm{CO}$ desorption and $\mathrm{CO}$ oxidation were determined from the thermal desorption spectra by varying the initial coverage of one reactant. The coadsorbed layers were formed by sequential exposure of the reactants. During the exposures, the surface temperature was $300 \mathrm{~K}$, where the oxidation reaction is negligibly slow. Hence, the adsorption kinetics of oxygen (CO) on a surface partially covered with CO (oxygen) could be measured by a knowledge of the adsorption kinetics of the first component and a mass balance for the second component from the thermal desorption spectra. The results of this study are as follows. The kinetics of $\mathrm{CO}$ oxidation and $\mathrm{CO}$ desorption may be modeled accurately by Arrhenius expressions. The activation energy for $\mathrm{CO}$ desorption, which depends on the coverages of both $\mathrm{CO}$ and oxygen, may vary from 10 to $36 \mathrm{kcal} \mathrm{mol}^{-1}$, but maintains near $16 \mathrm{kcal} \mathrm{mol}^{-1}$ where the steady state rate of CO oxidation is rapid, i.e. on a surface partially covered with oxygen near $600 \mathrm{~K}$. The pre-exponential factor associated with this activation energy is $10^{6} \mathrm{~s}^{-1}$. The activation energy for $\mathrm{CO}$ oxidation via the Langmuir-Hinshelwood mechanism is relatively insensitive to the composition of the adlayer and is approximately equal to $12 \mathrm{kcal} \mathrm{mol}^{-1}$. The pre-exponential factor for the oxidation reaction is $3 \times 10^{-9}$ or $3 \times 10^{-10} \mathrm{~cm}^{2}$ $\mathrm{s}^{-1}$, for surface temperatures near 400 and $550 \mathrm{~K}$, respectively. This variation as well as the small value of the pre-exponential factor indicates diffusion of the reactants on the surface, rather than the adatom-admolecule reaction, may limit the oxidation rate on the surface.

The initial probability of adsorption of $\mathrm{CO}$ on clean or oxidized $\operatorname{Ir}(110)$ at $300 \mathrm{~K}$ is unity, regardless of the coverage of chemisorbed oxygen, indicating oxygen does not block sites for $\mathrm{CO}$ chemisorption. However, if sufficient oxygen is chemisorbed, the adsorption kinetics of $\mathrm{CO}$ are of the Langmuir type and are second order in the coverage of $\mathrm{CO}$. Both chemisorbed oxygen and CO block sites for oxygen chemisorption so that the adsorption kinetics of oxygen are of the Langmuir type, vary as second order in the coverages of $\mathrm{CO}$ and oxygen, but also depend on the structure of the chemisorbed layer. If the sites occupied by $\mathrm{CO}$ are accounted for, the initial probability of adsorption of oxygen at a surface temperature of $300 \mathrm{~K}$ is 0.27 on the clean surface, the same as found in the absence of $\mathrm{CO}$; but it is 0.035 on the oxidized surface, which is an order of magnitude smaller than the value obtained in the absence of $\mathrm{CO}$.

Steady State Experiments ${ }^{2}$ : The steady state rates of $\mathrm{CO}_{2}$ production from $\mathrm{CO}$ and $\mathrm{O}_{2}$ were measured over $\mathrm{Ir}(110)$ for surface temperatures between 300 and $1000 \mathrm{~K}$, for partial pressures of the reactants between $10^{-8}$ and $3 \times 10^{-6}$ Torr, and for partial pressure ratios $\left(P_{\mathrm{CO}} / P_{\mathrm{O}_{2}}\right)$ between 0.1 and 10 . Rate expressions developed from transient reactions were combined into a model that both qualitatively and quantitatively predicts trends in the steady state measurements. However, the following four phenomena limit the applicability of this model. (1) The activation energy for CO desorption depends markedly upon the composition of the adlayer. (2) Diffusion in the adlayer may limit the rates of $\mathrm{CO}$ desorption and $\mathrm{CO}$ oxidation, but this effect can be included empirically in the rate expression. (3) The catalyst surface is oxidized at temperatures where the steady state rate of $\mathrm{CO}$ oxidation is rapid, i.e., a second type of atomically adsorbed oxygen forms irreversibly near $700 \mathrm{~K}$. (4) Hysteresis in the rate of $\mathrm{CO}_{2}$ production with temperature occurs in the steady state reaction, which cannot be attributed solely to oxidation of the catalyst.

The experimental results are as follows. Below $600 \mathrm{~K}$, where the oxidation rate increases with surface temperature, the rate is inversely proportional to the partial pressure of $\mathrm{CO}$, but it is proportional to the square of the partial pressure of oxygen. The unusual variation in the rate with the oxygen pressure may be associated with the diffusion of chemisorbed oxygen on the surface. If the steady state rate is measured below 600 $\mathrm{K}$ as the surface temperature is increased, the apparent activation energy and pre-exponential factor for the steady state rate on clean $\operatorname{Ir}(110)$ are $14 \pm 2 \mathrm{kcal} \mathrm{mol}^{-1}$ and $2 \times 10^{25 \pm 1}$ 
molecules $\mathrm{cm}^{-2} \operatorname{Torr}^{-1} \mathrm{~s}^{-1}$. However, if the rate is measured as the temperature is decreased, these two quantities vary considerably due to hysteresis in the oxidation rate. Above 600 $K$, where the steady state rate decreases with surface temperature, the oxidation rate is proportional to the partial pressure of $\mathrm{CO}$, but it is independent of the partial pressure of oxygen. Regardless of whether the surface is clean or oxidized and whether the surface temperature is being increased or decreased, the apparent activation energy and pre-exponential factor for the overall rate coefficient are $-4 \pm 2 \mathrm{kcal}$ $\mathrm{mol}^{-1}$ and $2 \times 10^{19 \pm 1}$ molecules $\mathrm{cm}^{-2} \mathrm{Torr}^{-1} \mathrm{~s}^{-1}$. The temperature associated with the maximum oxidation rate at steady state occurs near the intersections of the asymptotic curves above and below $600 \mathrm{~K}$, and it is inversely proportional to the logarithm of the ratio of the $\mathrm{CO}$ partial pressure to the oxygen partial pressure.

a) Supported by the National Science Foundation under Grant No. CHE7714976.

b) Camille and Henry Dreyfus Foundation Teacher-Scholar.

c)Present address: Proctor and Gamble Co., Miami Valley Laboratories, Cincinnati, Ohio 45247.

IJ. L. Taylor, D. E. Ibbotson, and W. H. Weinberg, Surf. Sci. 90, 37 (1979).

2J. L. Taylor, D. E. Ibbotson, and W. H. Weinberg, J. Catalysis 62, 1 (1980).

\title{
Summary Abstract: Decomposition of NO on clean Pt near atmospheric pressures ${ }^{\text {a) }}$
}

\author{
L. D. Schmidt and M. J. Mummey ${ }^{\text {b) }}$ \\ Department of Chemical Engineering and Materials Science, University of Minnesota, Minneapolis, Minnesota 554455 \\ (Received 19 September 1980; accepted 18 November 1980)
}

PACS numbers: 82.30.Lp, 82.65.Jv, 82.80.Pv, 82.20.Pm

Nitric oxide decomposition on clean Pt is studied at pressures and temperatures comparable to those in the automotive catalytic converter. A high pressure reaction cell inside a UHV chamber is used to clean the surface before reaction and determine its cleanliness and adsorbate coverages after reaction. The objectives of this research are to examine kinetics on a well defined surface and to determine which binding states of adsorbates are involved in high pressure reaction.

The Pt ribbon is cleaned by heating in $\mathrm{O}_{2}$ and vacuum as determined by AES. It is then sealed in a $35 \mathrm{~cm}^{3}$ stainless steel cup through which $\mathrm{NO}$ and $\mathrm{O}_{2}$ are passed at pressures between $10^{-4}\left(1.3 \times 10^{-2} \mathrm{~Pa}\right)$ and 1000 Torr. Reaction rates are measured in either batch or flow configurations. After reaction the pressure is reduced to $10^{-9}$ Torr, and the ribbon is examined by AES and TPD of $\mathrm{NO}, \mathrm{N}_{2}, \mathrm{O}_{2}$, and $\mathrm{N}_{2} \mathrm{O}$. In another set of experiments TPD is carried out at high pressures under reaction conditions to determine the coverages during reaction.

The reaction rate was measured for NO pressures between $10^{-4}$ and 30 Torr, temperatures between 500 and $1400 \mathrm{~K}$, and rates between $10^{14}$ and $10^{18}$ molecules $\mathrm{cm}^{-2} \mathrm{~s}^{-1}$. Over the entire range of temperatures and pressures the rate attained a steady state within a few seconds and could be fit quantitatively by a Langmuir-Hinshelwood rate expression,

$$
r=\frac{k_{\mathrm{R}} K_{\mathrm{NO}} \mathrm{P}_{\mathrm{NO}}}{1+K_{\mathrm{NO}} \mathrm{P}_{\mathrm{NO}}+K_{\mathrm{O}_{2}} \mathrm{P}_{\mathrm{O}_{2}}}
$$

to within an accuracy of $\pm 20 \%$. The reaction rate coefficient $k_{R}$ and adsorption equilibrium constants $K_{\mathrm{NO}}$ and $K_{\mathrm{O}_{2}}$ were found to have Arrhenius temperature dependences

$$
\begin{gathered}
k_{R}\left(\text { molecules } \mathrm{cm}^{-2} \mathrm{~s}^{-1}\right)=8 \times 10^{19} \exp [-13500 / \mathrm{RT}] \\
K_{\mathrm{NO}}\left(\text { Torr }^{-1}\right)=7 \times 10^{-4} \exp [8250 / \mathrm{RT}]
\end{gathered}
$$

and

$$
K_{\mathrm{O}_{2}}\left(\operatorname{Torr}^{-1}\right)=1.6 \exp [9550 / \mathrm{RT}]
$$

with energies in $\mathrm{cal}^{\mathrm{mol}} \mathrm{m}^{-1}$.

The simple interpretation of this rate expression is the unimolecular decomposition of NO with strong competitive adsorption of oxygen. The heats of adsorption of $\mathrm{NO}$ and $\mathrm{O}_{2}$ are 8.5 and $10 \mathrm{kcal} \mathrm{mol}^{-1}$ respectively, and the $\mathrm{P}_{\mathrm{O}_{2}}^{-1}$ dependence suggests that the inhibiting state of oxygen is molecularly adsorbed.

The adsorption parameters measured in reaction of NO are 